Document downloaded from:

http://hdl.handle.net/10251/81250

This paper must be cited as:

Balart Gimeno, JF.; Fombuena Borrás, V.; Fenollar Gimeno, OA.; Boronat Vitoria, T.; Sánchez Nacher, L. (2016). Processing and characterization of high environmental efficiency composites based on PLA and hazelnut shell flour (HSF) with biobased plasticizers derived from epoxidized linseed oil (ELO). Composites Part B: Engineering. 86:168-177. doi:10.1016/j.compositesb.2015.09.063.

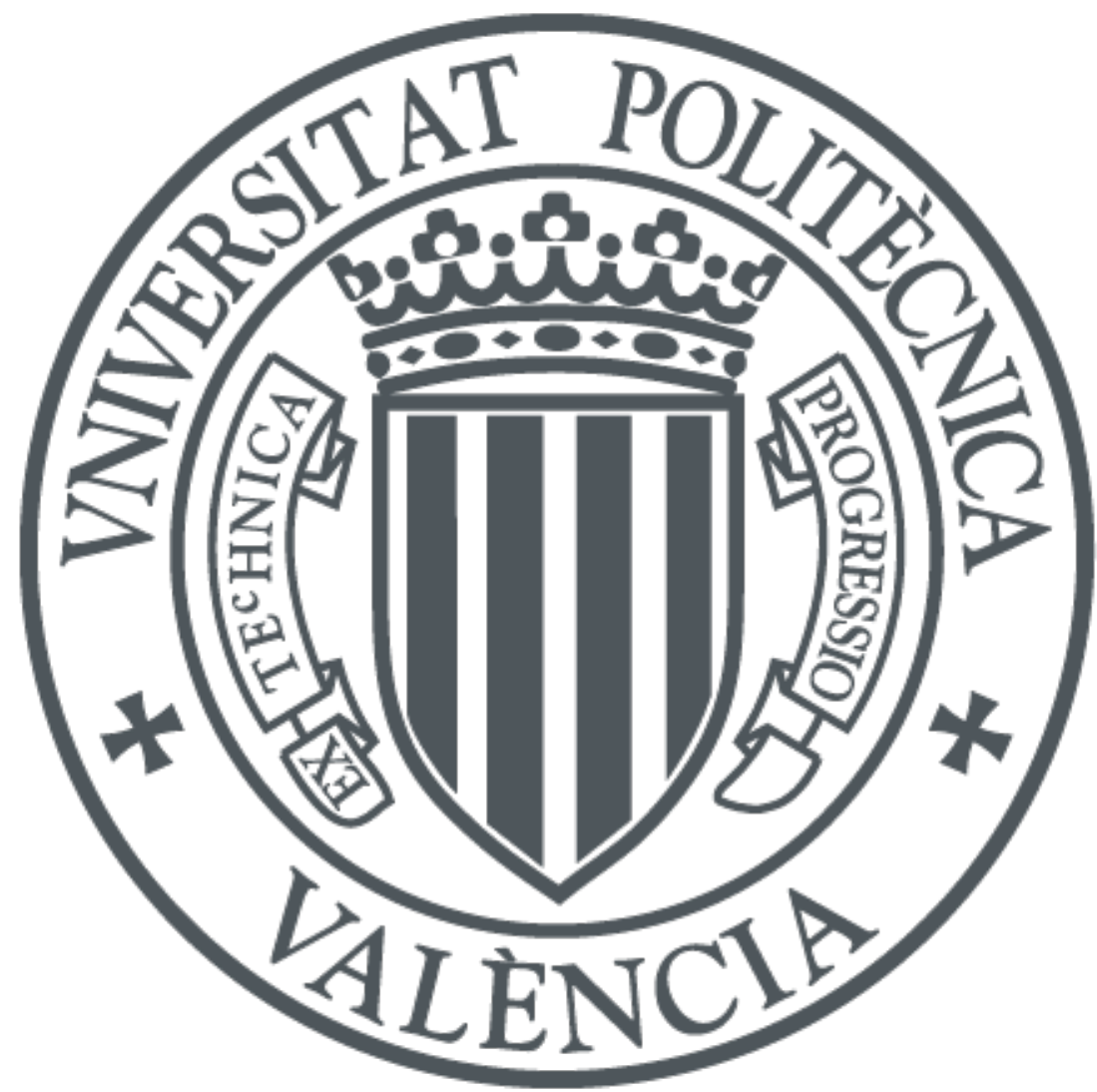

The final publication is available at

Copyright Elsevier

Additional Information 


\title{
"Processing and characterization of high environmental efficiency composites based on PLA and hazelnut shell flour (HSF) with biobased plasticizers derived from epoxidized linseed oil (ELO)"
}

\author{
J.F. Balart ${ }^{1}$, V. Fombuena, O. Fenollar, T. Boronat, L. Sánchez-Nacher \\ Instituto de Tecnología de Materiales (ITM) \\ Universitat Politècnica de València (UPV) \\ Plaza Ferrandiz-Carbonell, s/n, 03801 Alcoy, Alicante, Spain
}

\begin{abstract}
Different amounts of epoxidized linseed oil (ELO) have been added to poly(lactic acid)-PLA composites with hazelnut shell flour (HSF) to provide a plasticizing effect and improve the low intrinsic ductile properties of PLA/HSF composites. Mechanical, thermal, thermo-mechanical and dynamic mechanical properties have been studied in terms of the weight percentage ELO. Mechanical resistant properties in both tensile and flexural tests decrease with wt.\% ELO while a remarkable increase with wt.\% ELO is obtained. These results reveal a clear plasticization effect of ELO but, in addition, internal structure of PLA/HSF/ELO composites shows good PLA-HSF (matrix-particle) interactions so that indicating that ELO also provides a coupling effect between PLA matrix and HSF filler. ELO addition leads to a decrease in storage modulus ( $\left.G^{\prime}\right)$ obtained by dynamic mechanical thermal analysis (DMTA) in torsion mode thus giving clear evidence of the plasticization effect of ELO. Overall, the use of ELO in PLA/HSF composites is an attracting way to improve the low intrinsic fragility of these green
\end{abstract}

\footnotetext{
${ }^{1}$ Corresponding author: J.F. Balart, tel.:+34 966528424, fax: +34 966528433, e-mail: jfbalart@dimm.upv.es
} 
composites; furthermore, ELO provides an improvement on thermal stability and a coupling effect between the polymer matrix and the surrounding lignocellulosic filler.

Keywords: A. Particle-reinforcement; B. Interface/interphase; D. Mechanical testing; E. Injection moulding.

\section{1.- Introduction.}

In the last years, a remarkable increase in the development of high environmentally friendly materials has been detected in the field of polymers and polymer composites. The high concern of society about environment protection has promoted the development of new "eco", "bio" or "green" materials. One of the main features of these new materials is their natural origin and/or potential biodegradability. So that, substitution of commodity plastics from petrochemical origin by biobased polymers is a challenge for the plastics and polymer composite industries as they do not generate harmful wastes at the end of the life cycle. With regard to polymer composites, the use of natural reinforcements (fibers, particulates, flours) such as vegetable fibers (jute, hemp, flax, sisal, Posidonia oceanica, etc.) or lignocellulosic particles (sawdust, peanut shell, almond shell, rice husk, spend coffee ground, etc.)[1-6] and other cellulose particles, contributes to obtain high environmentally friendly composite materials with new and attracting uses. These new uses include applications of conventional wood plastic composites (WPCs) in the building industry (outdoor deck floors, fences, window and door frames, railings, etc.) as well as in some technologic sectors such as automotive (parcel shelves, front and rear door linens, seat backs, headliners, etc.)[7].

Poly(lactic acid), PLA is one of the most widely used biopolymer in the field of plastics (packaging) and green composites. Poly(lactic acid) is obtained by 
polymerization of lactic acid which is a natural monomer obtained by fermentative processes from sugar-rich compounds such as cellulose and starches (potato, corn, wheat, sugarcane, etc.)[8, 9]. PLA is a fragile thermoplastic with good mechanical resistance similar to polystyrene, PS. The molecular chain structure is similar to most thermoplastics and it can be manufactured by conventional processing techniques. In the last years, some researches have focused on the development of fully biobased composites with natural reinforcements, mainly natural fibers or woof flours. Hazelnut shell is a byproduct of the food industry. It is an industrial waste, so that it is cost effective and upgrading it is an interesting challenge. This filler can be grinded to give a lignocellulosic flour that can provide wood like appearance to polymer composites. It can be used as reinforcement/filler with a wide variety of polymeric matrices to give wood-like materials that contribute to preserve forestry resources[10-21]. Although these composites are attractive for some technical uses, one important drawback is their excessive fragility, which results from the high intrinsic account the relatively low hydrophilic nature of PLA and the extremely high hydrophilic nature of the lignocellulosic filler, poor matrixparticle interactions are achieved thus leading to stress concentration phenomena that also contributes to fragility. For this reasons, research on how to reduce fragility of PLA-based composites is being investigated. One approach is focused on the use of compatible plasticizers for PLA and another approach considers the use of compatibilizer agents to act as a bridge between the hydrophobic PLA matrix and the highly hydrophilic surrounding particles.

In general terms, the use of plasticizers lead to a decrease in the PLA glass transition temperature ( $\mathrm{T}_{\mathrm{g}}$ PLA); they also favor cold crystallization and the resulting material is more flexible. Yu et al. concluded that poly(ethylene glycol), PEG is an effective plasticizer for PLA and contributes to a remarkable improvement on the impact 
strength of PLA. On the other PEG-plasticized PLA shows very low migration levels. Oligomeric lactic acid (OLA) gives excellent plasticizing properties to PLA as reported by Burgos et al. with a noticeable improvement on PLA ductile properties. Other research works focus on monomeric plasticizers (lactic acid, citrate esters, low-molecular weight ester-type, etc.), oligomeric and polymeric plasticizers such as commercial adipates (DOA - (bis(2-ethylhexyl) adipate), lactic-acid derived polymers, poly(ethylene glycol), poly(propylene glycol), etc. [8, 22-29].

On the other hand, the use of coupling agents or compatibilizers provides intense PLA matrix-lignocellulosic filler interactions that contribute to decrease fragility. Chemical coupling agents such as N,N-(1,3-phenylene dimaleimide) and 1,1(methylenedi-4,1-phenylene) bismaleimide contribute to improved adhesion between PLA and dispersed lignocellulosic fillers thus leading to a remarkable increase in overall mechanical performance[10,30]. Other successful coupling systems include silane-based coupling agents, alkali soaking, maleic anhydride treatment. All these coupling systems have demonstrated their usefulness in improving PLA-cellulosic particle interactions, with a considerable increase in elongation at break of PLA/cellulosic composites as well as reducing their impact behavior[31-37]. Other researchers analyzed the effectiveness of acrylic core-shell rubbers, coconut oil, sodium-montmorillonite, ionic liquids, etc. as coupling agents with a noticeable reduction of fragility [38-41].

Epoxidized linseed oil (ELO) is a vegetable obtained by an epoxidation process of industrial oil coming from flax seed. Its main features are null volatility, extremely low migration tendency and high resistance to extraction in aqueous media or hydrocarbons (natural or biobased). Some authors have proved the efficiency of epoxidized vegetable oils as plasticizers for PLA and other polymers such as poly(vinyl chloride), PVC. Ali et al. concluded that epoxidized soybean oil (ESBO) offers good plasticizing effect to PLA 
with a remarkable increase in flexibility. Epoxidized palm oil (EPO) was tested by Silverajah et al. as plasticizer for PLA with an optimum amount of 1 wt.\% with a noteworthy improvement of mechanical and thermal properties. Prempeh et al. used epoxidized sunflower oil (ESFO) to give high elongation at break to PLA (four times higher than unplasticized PLA)[23-25, 42-47].

The main aim of this study is to reduce the high intrinsic fragility of poly(lactic acid), PLA - hazelnut shell flour (HSF) by using a biobased plasticizer from epoxidized linseed oil (ELO). Mechanical, thermal and thermomechanical properties of PLA - HSF green composites are evaluated in terms of the epoxidized linseed oil (ELO) load in the 0 -22.5 wt. \% range.

\section{2.- Experimental.}

\section{1.- Materials.}

Poly(lactic acid), PLA commercial grade Ingeo 6201D was supplied by NatureWorks LLC (Minnesota, USA). This grade is characterized by a melt flow index in the $15-30 \mathrm{~g} / 10$ min range and a density of $1.24 \mathrm{~g} \mathrm{~cm}^{-3}$.

Hazelnut shell waste (Corylus avellana) was obtained from the food industry and subjected to a grinding process to an average particle size of $63 \mu \mathrm{m}$ to give a homogeneous flour (hazelnut shell flour, HSF). Hazelnut shell was grinded in an ultra centrifugal mill from Retsch GmbH (Hann, Germany) at a rotating speed of $10000 \mathrm{rpm}$.

Epoxidized linseed oil (ELO), CAS number 8016-11-3 was used as plasticizer in PLA - HSF green composites. ELO with an oxyrange oxygen content of $8 \%$ and a iodine value of 5\% was supplied by Traquisa S.L. (Barcenola, Spain). This epoxidized oil is characterized by a molecular weight of about $1037 \mathrm{~g} \mathrm{~mol}^{-1}$, a density of $1.05-1.06 \mathrm{~g} \mathrm{~cm}^{-3}$ at $20^{\circ} \mathrm{C}$ and a viscosity of $8-11 \mathrm{p}$ at $25{ }^{\circ} \mathrm{C}$. It shows high thermal stability with a 
flammability temperature of $287^{\circ} \mathrm{C}$ and it is not water-soluble. The average fatty acid profile is: 3-5\% stearic acid, 5-7\% palmitic acid, 14-20\% linoleic acid, 18-26\% oleic acid and 51-56\% linolenic acid.

\section{2.- Manufacturing of PLA - HSF composites with different ELO loads.}

Initially, both poly(lactic acid) pellets and hazelnut shell flour were dried at $60{ }^{\circ} \mathrm{C}$ for $24 \mathrm{~h}$ to remove moisture. After this, PLA, HSF and ELO were weighed according to the compositions defined in Table 1.

\section{Table 1}

All four compositions were extruded in a twin screw co-rotating extruder from DUPRA S.L. (Castalla, Spain). The temperature profile in the extruder was set to $176^{\circ} \mathrm{C}$, $180^{\circ} \mathrm{C}, 185^{\circ} \mathrm{C}$ and $192{ }^{\circ} \mathrm{C}$ (from the hopper to the die) and the rotating speed was set to $40 \mathrm{rpm}$. After extrusion, the different compositions were pelletized for further processing by injection molding in a Meteor 270/75 from Mateu \& Solé (Barcelona, Spain). The injection temperature was set to $190^{\circ} \mathrm{C}$, the cavity filling time was 1 second and the cooling time was set in 10 seconds. Standard samples for different tests were obtained with a thickness of $4 \mathrm{~mm}$.

\section{3.- Testing and characterization.}

Mechanical Testing.

Tensile properties of ELO modified PLA - HSF composites were obtained as indicated in the UNE-EN-ISO 527-1 standard in a universal test machine ELIB 30 from

S.A.E. Ibertest (Madrid, Spain). The selected load cell was $5 \mathrm{kN}$. Samples with a total length of $150 \mathrm{~mm}$ and a cross section of $10 \mathrm{x} 4 \mathrm{~mm}^{2}$ (type 1A) were subjected to tensile 
tests at a crosshead speed was set to $10 \mathrm{~mm} \mathrm{~min}^{-1}$. The same machine was used for flexural characterization of composites by following the guidelines of the ISO 178 with a crosshead rate of $5 \mathrm{~mm} \mathrm{~min}{ }^{-1}$. The impact strength was tested in a $1 \mathrm{~J}$ Charpy pendulum from Metrotec S.A. (San Sebastián, Spain) as suggested by ISO 179. Finally, Shore D hardness of PLA - HSF with different ELO content was measured in a Shore D durometer mod. 673-D from J. Bot S.A. (Barcelona, Spain) following the UNE-EN ISO 868. At least five different samples were tested for each mechanical property and average values were calculated.

\section{Microscopic characterization.}

Fractured surfaces from impact tests and cryofractured surfaces of PLA - HSF with different ELO content were observed by field emission scanning electron microscopy (FESEM), mod. Zeiss Ultra 55 de Oxford Instruments (Abingdon, United Kingdom) at an acceleration voltage of $2 \mathrm{kV}$. Samples were covered with a thin platinum layer in a high vacuum sputter coater EM MED20 from Leica Microsystem (Milton Keynes, United Kingdom).

\section{Thermal and thermo-mechanical characterization.}

Thermal transitions of PLA - HSF composites with varying ELO content were obtained by differential scanning calorimetry (DSC) in a DSC calorimeter mod. 821 from Mettler Toledo Inc. (Schwerzenbach, Switzerland). Samples with an average weight of 7-10 mg were subjected to a three step program with an initial heating cycle from $30^{\circ} \mathrm{C}$ to $200{ }^{\circ} \mathrm{C}$ at $10^{\circ} \mathrm{C} \min ^{-1}$ to remove thermal history followed by a cooling to $-50{ }^{\circ} \mathrm{C}$ at a heating rate of $-10{ }^{\circ} \mathrm{C}$ min-1. Finally, a second heating cycle from $-50{ }^{\circ} \mathrm{C}$ up to $350{ }^{\circ} \mathrm{C}$ at 
$10{ }^{\circ} \mathrm{C} \min ^{-1}$ was used to evaluate all thermal transitions. All thermal cycles were performed in presence of a nitrogen atmosphere at $66 \mathrm{~mL} \mathrm{~min}^{-1}$.

Thermogravimetric analysis (TGA) was used to evaluate thermal stability of PLA - HSF composites at high temperatures. The heating program was from $30^{\circ} \mathrm{C}$ to $700{ }^{\circ} \mathrm{C}$ at a heating rate of $20{ }^{\circ} \mathrm{C} \mathrm{min}-1$ in nitrogen atmosphere $\left(66 \mathrm{~mL} \mathrm{~min}{ }^{-1}\right)$. TGA characterization was carried out in a TGA/SDTA 851 thermobalance from Mettler Toledo Inc. (Schwerzenbach, Switzerland).

Vicat softening temperature (VST) was obtained as described in ISO 306 by using a load of $5 \mathrm{~kg}$ and a heating rate of $50{ }^{\circ} \mathrm{C} \mathrm{h}^{-1}$. Additionally, the heat deflection temperature (HDT) was obtained following the guidelines of the ISO 75 and ASTM D 648 with a load of $296 \mathrm{~g}$ and a heating rate of $120^{\circ} \mathrm{C} \mathrm{h}^{-1}$. Both VST and HDT values were determined in a VICAT-HDT station from Metrotec S.A. (San Sebastián, Spain). Dimensional stability was studied by determining the coefficient of linear expansion (CLTE) of PLA - HSF composites with varying ELO content in a thermomechanical analyzer Q400 from TA Instruments (Delaware, USA). The heating program was comprised between $0{ }^{\circ} \mathrm{C}$ and $140{ }^{\circ} \mathrm{C}$ with a constant heating rate of $2^{\circ} \mathrm{C} \mathrm{min}^{-1}$ and a constant load of $0.02 \mathrm{~N}$.

Dynamic Mechanical Analysis, DMA, in torsion mode were carried out in an oscillatory rheometer AR-G2 (TA Instruments, New Castle, EEUU) equipped with an environmental test chamber (ETC) with a rectangular torsion clamp system for solid samples. Samples sizing 40x 10x4 $\mathrm{mm}^{3}$ were subjected to a dynamic temperature program ramp from $30^{\circ} \mathrm{C}$ to $120^{\circ} \mathrm{C}$ at a heating rate of $2^{\circ} \mathrm{C} \mathrm{min}^{-1}$, with the following conditions: maximum deformation $(\gamma)=0.1 \%$ and constant frequency of $1 \mathrm{~Hz}$.

\section{3.- Results and discussion.}




\section{1.- Effect of biobased plasticizer (ELO) content on the mechanical properties of the PLA - HSF composites.}

Mechanical behavior of PLA - HSF containing $20 \mathrm{wt} . \%$ HSF is characterized by high fragility (see Table 2). The elastic modulus is relatively high, with values around $1019 \mathrm{MPa}$, thus indicating it is a rigid material with high tensile strength but low elongation at break (3\%). The inherent fragility of poly(lactic acid) together with the poor matrix-particle interaction lead to a pronounced fragility on this composite.

\section{Table 2}

The change in mechanical behavior of PLA - HSF composites with ELO content is a clear evidence of the plasticization effect that ELO provides. As the ELO content increases, we observe a clear decreasing tendency on both tensile strength and elastic modulus while the elongation at break increases with ELO content. Unmodified PLA 20 wt.\% HSF composite possesses and elastic modulus of $1019 \mathrm{MPa}$ and this decreases up to values of $751 \mathrm{MPa}$ and $590 \mathrm{MPa}$ (a percentage decrease of $26 \%$ and $42 \%$ respectively) for composites containing $15 \mathrm{wt} . \%$ and $22.5 \mathrm{wt} . \%$ ELO thus indicating a clear plasticizing effect. Same behavior can be observed for tensile strength with an initial value of $45 \mathrm{MPa}$ (unmodified PLA - 20 wt.\% HSF composite) and a reduction up to 15.3 MPa for the composite containing $22.5 \mathrm{wt}$.\% ELO which represents a percentage decrease of about $66 \%$. The remarkable decrease in tensile strength is representative for inappropriate PLA-ELO interactions. The plasticizer excess can appear as a dispersed phase in the PLA matrix with a negative effect on homogeneity that promotes a decrease in tensile strength. High plasticizer contents produce intense plasticizer-plasticizer interactions that lead to a phase separation[47]. Chieng et al. concluded that for high 
plasticizer contents, only a small part is directly in contact among the interface area while the excess is dispersed in the polymeric matrix. This phenomenon highly affects homogeneity and a decrease in tensile strength on PLA - $20 \mathrm{wt} . \%$ HSF composite with varying ELO content[23-25, 46].

On the other hand, the elongation at break is highly increased with ELO content. Unmodified PLA - 20 wt.\% HSF composite is characterized by a relatively low elongation at break value of about 3\%. Composites containing 7.5 wt.\% ELO are characterized by slightly higher elongation at break with average values of $4.2 \%$ but we can clearly see the plasticizing effect in PLA - 20 wt.\% HSF composites containing 15 wt. $\%$ and 22.5 wt. $\%$ ELO with elongation at break close to $11 \%$ and $17 \%$ respectively. This means that ELO provides a clear plasticizing effect to PLA - 20 wt.\% HSF composites. Presence of ELO promotes less intense intermolecular forces between PLA macromolecular chains thus leading to improved chain mobility which is responsible for the abovementioned decrease in stiffness as well as the clear improvement of ductile properties[22, 26, 42].

The effect of ELO content on flexural properties can be explained by observing data in Table 2. In a similar way to tensile properties, the flexural modulus and strength (mechanical resistant properties) are reduced with increasing ELO content. With regard to flexural modulus, it is reduced by $10 \%$ in PLA - 20 wt.\% HSF composites containing 7.5 wt.\% ELO. The flexural modulus is reduced to the half for composites containing 22.5 wt.\% ELO. As indicated previously, epoxidized linseed oil (ELO) molecules enable polymer chain mobility so that the material is less stiff. If we observe the evolution of the flexural strength it changes from 83.7 MPa (unmodified PLA - 20 wt.\% composite) up to minimum values of $29.5 \mathrm{MPa}$ for composites containing $22.5 \mathrm{wt} \%$ ELO, which represents a percentage decrease of about $65 \%$. Similar tendency can be observed for 
Shore D hardness of PLA - 20 wt.\% HSF composites with varying ELO content as abovementioned for other mechanical resistant properties.

\section{2.- Effect of biobased plasticizer (ELO) content on morphological of PLA - HSF} composites.

FESEM technique was used to study the effect of different ELO content on morphology of cryofractured surfaces to show in a qualitative way the internal structure and give evidence of the potential interactions. Fig. 1 shows FESEM images of PLA - 20 wt.\% HSF composites with varying ELO content.

\section{Figure 1}

Fig. 1a \& 1b correspond to unmodified PLA - 20 wt.\% composite. We can clearly see the lack of interaction between the lignocellulosic particles and the surrounding PLA matrix. This is evidenced by a small gap between the particle and the matrix, which is responsible for material discontinuity. This phenomenon does not allow optimum load transfer between particle and the matrix leading to stress concentration phenomena which has a consequence the fragility of the material as it has been observed in the previous section. In addition, the fracture surface is very smooth and homogenous due to the intrinsic fragility of poly(lactic acid) polymers.

Nevertheless, composites containing 7.5 wt.\% ELO show a remarkably different surface fracture morphology as observed in Fig. 1c \& Fig. 1d for different magnifications. Improved particle-polymer interaction can be observed by a reduction of the gap between the dispersed lignocellulosic particle and the surrounding PLA matrix and the overall discontinuity is remarkably reduced. This interaction allows load transfer between PLA 
matrix and dispersed HSF particles and this leads to improved ductile properties such as elongation at break. PLA can be plasticized with relatively low amounts of epoxidized vegetable oils as reported by other authors and PLA is not absolutely miscible with epoxidized vegetable oils[23, 24, 44, 47]. This lack of complete miscibility is evidenced by observation of fractured surfaces. The fractured surfaces of composites with high ELO content are less homogeneous and we can find round shape irregularities and/or microvoids uniformly dispersed in the PLA matrix. This rounded shapes correspond to ELO-rich phase that has not mixed with poly(lactic acid) polymer chains due to this partial miscibility which leads to a phase separation[43, 46]. For composites with higher ELO content, the fractured surface morphology is similar but the particle-polymer interactions are pronounced. For example, the composite containing $15 \mathrm{wt} . \%$ ELO (Fig. 1e \& Fig. 1f) shows more intense adhesion phenomena between the lignocellulosic filler and the surrounding matrix. These strong interactions contribute to lowering the intrinsic fragility thus leading to increased elongation at break (around 11\%). Fig. 1g \& Fig. 1h correspond to PLA - 20 wt.\% HSF composite with 22.5 wt.\% ELO and show good particle-matrix adhesion. The gap between the HSF particles and the surrounding area is very small so that the composite offers higher ductility[31, 33, 36].

This remarkable change in surface morphology is due the double action that ELO provides to PLA - $20 \mathrm{wt} . \%$ HSF composites; on the one hand the plasticizing effect of ELO leads to improved chain mobility but on the other hand, ELO provides a coupling effect between lignocellulosic HSF particles and plasticized PLA matrix thus leading to a synergistic effect. It is important to take into account that epoxidized linseed oil is characterized by high polarity due to the oxirane groups. The oxiranic oxygen content (OOC) of ELO is close to $8 \%$ which is higher compared to other commercial epoxidized vegetable oils such as epoxidized soybean oil (ESBO). The epoxide group can react with 
the hydroxyl groups in lignocellulosic filler to form strong interactions. These reactions (see Fig. 2) are favored by temperature during manufacturing (extrusion + injection molding)[23, 24, 42]. Wang et al. concluded that this mechanism decreases the overall polarity of lignocellulosic particles which favors good particle dispersion in hydrophobic (or low hydrophilic) polymeric matrices such as PLA. On the other hand, epoxide groups in ELO can react with terminal hydroxil groups in poly(lactic acid) macromolecular chains as proposed in Fig. 2. The high oxiranic oxygen content of ELO enables different reaction points with PLA[23, 24, 29, 41, 44, 47]. These two combined effects: PLA-ELO interactions and HSF-PLA interactions allow ELO to act as a coupling agent between poly(lactic acid) and hazelnut shell flour with a remarkable increase in polymer-particle adhesion as described previously. This interactions are optimum for ELO contents over 7.5 wt.\%. For relatively low ELO amounts (7.5 wt.\%) ELO does not fully wet lignocellulosic particles due to the high surface area of HSF particles; so that, ELO-HSF interactions are not optimum (Fig. 1d) and the corresponding composite is characterized by relatively low ductility (see Table 2).

\section{Figure 2}

\section{3.- Effect of biobased plasticizer (ELO) content on thermal and thermo-mechanical properties of PLA - HSF composites.}

Fig. 3 shows a comparative plot of the DSC thermograms of PLA - 20 wt.\% HSF composites with varying ELO content. We can see a decrease in the glass transition temperature $\left(\mathrm{T}_{\mathrm{g}}\right)$ with increasing ELO content. The glass transition temperature of unmodified PLA - 20 wt.\% HSF is located at about $66.5^{\circ} \mathrm{C}$ and this is moved to lower temperatures in the $60{ }^{\circ} \mathrm{C}$ range for composites with 7.5 wt.\% ELO. Higher ELO contents 
(i.e. 22.5 wt.\%) lead to glass transition temperatures of $58{ }^{\circ} \mathrm{C}$. This is due to the plasticization effect of ELO as ELO presence promotes chain mobility. Epoxidized linseed oil molecules are placed between poly(lactic acid) macromolecules thus allowing polymer chain motions due to the internal lubricant effect. On the other hand, only one glass transition temperature can be observed so that indicating good compatibility between ELO and PLA in this range of compositions[22-24, 42, 45].

\section{Figure 3}

The cold crystallization temperature $\left(\mathrm{T}_{\mathrm{cc}}\right)$ does not change in a great extent $(1-2$ $\left.{ }^{\circ} \mathrm{C}\right)$ with increasing ELO content. With regard to the melt temperature $\left(\mathrm{T}_{\mathrm{m}}\right)$ it changes from $170{ }^{\circ} \mathrm{C}$ (unmodified PLA - 20 wt. $\%$ HSF) up to $167^{\circ} \mathrm{C}$ for composites containing 22.5 wt.\% ELO. So that, we can conclude that presence of ELO in PLA - HSF composites does not affect in a great extent the melt process[23, 24].

Another important thing is that poly(lactic acid) is a semicrystalline polymer, so that the influence of ELO on PLA crystallinity degree ( $\left.\mathrm{X}_{\mathrm{c} \text { PLA }}\right)$ has also been studied by using the following equation:

$$
X_{C P L A}(\%)=\left[\frac{\left|\Delta H_{m}\right|-\left|\Delta H_{C C}\right|}{\left|\Delta H_{100 \%}\right| \cdot w_{P L A}}\right] \cdot 100
$$

Where $\Delta \mathrm{H}_{\mathrm{m}}$ is the melt enthalpy (negative value due to the endothermic process), $\Delta \mathrm{H}_{\mathrm{cc}}$ is the cold crystallization enthalpy (positive value due to the exothermic process), $\Delta \mathrm{H}_{100 \%}$ is the melt enthalpy for theoretical $100 \%$ crystalline PLA (-93.7 $\left.\mathrm{J} \mathrm{g}^{-1}\right)$ and finally, WPLA is the weight fraction of PLA in PLA - $20 \mathrm{wt} . \%$ HSF composites with different ELO content $[8,14,27,35,48-50]$. 


\section{Table 3}

Table 3 shows a summary of the main thermal parameters in terms of the wt.\% ELO in PLA - 20 wt.\% HSF. Normalized enthalpy values $\left(\Delta \mathrm{H}_{\mathrm{cc}}\right.$ and $\left.\Delta \mathrm{H}_{\mathrm{m}}\right)$ have been corrected by considering the wt.\% PLA (excluding the dilution effect of HSF and ELO as these two components do not show thermal transitions in the typical melt and cold crystallization temperature range of PLA). If we observe the evolution of the corrected cold crystallization enthalpy $\left(\Delta \mathrm{H}_{\mathrm{cc}}\right)$, we see a slight increase with ELO content, which is directly related to the crystallinity increase as the plasticizer allows more intense polymer chain motion. The crystallinity of PLA in unmodified PLA - 20 wt.\% HSF composites is close to $15 \%$ due to the nucleating effect of cellulose in hazelnut shell flour particles[9, 14, 35]. The presence of ELO plasticizer allows chain mobility and this has a positive effect on crystallinity as polymer chains can rearrange to ordered/packed structures. The highest crystallinity value is detected for the composite with 7.5 wt. $\%$ ELO $\left(X_{c}=19 \%\right)$. Higher ELO contents lead to slightly lower crystallinity. This could be related to a phase separation between PLA and excess plasticizer as observed in FESEM images (Fig. 1)[25, 46, 47]. The melt temperature is not highly affected by presence of ELO but a slight decrease from $169.9^{\circ} \mathrm{C}$ up to values in the $167-168^{\circ} \mathrm{C}$ range can be observed.

With regard to the thermal stability of PLA - 20 wt.\% HSF composites with varying ELO percentages, Fig. 4 shows a plot comparison of the thermogravimetric curves (TGA). We can observe an increase in the thermal stability with increasing ELO content. The TGA curve of the unmodified PLA - $20 \mathrm{wt} \%$ HSF composite is placed to the left if compared to the TGA curves of composites containing different ELO contents. This means that degradation of unmodified composite occurs at lower temperatures. The 
degradation onset for unmodified composite is about $317^{\circ} \mathrm{C}$ and the degradation temperature range is relatively narrow. As the ELO content increases, the onset degradation temperature is moved to higher temperatures of about $335^{\circ} \mathrm{C}, 337^{\circ} \mathrm{C}$ and $339{ }^{\circ} \mathrm{C}$ for composites containing 7.5, 15 and 22.5 wt.\% ELO respectively[23, 24, 43, 44]. With regard the degradation endset temperature, it changes from $365^{\circ} \mathrm{C}$ for unmodified composite to $381^{\circ} \mathrm{C}$ for composite containing $22.5 \mathrm{wt} . \%$ ELO. It is important to remark that the main uses of epoxidized vegetable oils are as plasticizer and thermal stabilizers mainly for poly(vinyl chloride), PVC so that, ELO presence in PLA - 20 wt.\% HSF composites, contributes to improved thermal stability. Prempeh et al. concluded that this stabilizing effect could be attributed to formation of hydrogen bonds between poly(lactic acid) polymer chains and the plasticizer which can lead to improved thermal stability[45]. In addition ELO rich phase embedded in the PLA matrix also contributes to act as an oxidation barrier which also restricts permeation to degradation volatile compounds and promotes a delay in degradation process[46]. Regarding to the weight loss, similar residual weights are obtained with a main degradation step of about $90-$ 91\%. This is due to the fact that all composites contain $20 \mathrm{wt} \% \mathrm{HSF}$ and the residual weight is associated to the ashes generated by the combustion of the lignocellulosic filler.

\section{Figure 4}

In addition to the thermal transitions by DSC and degradation by TGA study, the coefficient of linear thermal expansion (CLTE) was determined by thermomechanical analysis (TMA) as it is representative for the dimensional stability. The main parameters (CLTE below and over glass transition temperature, $\mathrm{T}_{\mathrm{g}}$ ) from TMA characterization of PLA - 20 wt.\% HSF composites with different ELO content are summarized in Table 4. 
If we compare the CLTE below the $\mathrm{T}_{\mathrm{g}}$ we can see that the initial value of the unmodified PLA - $20 \mathrm{wt}$. $\%$ HSF composite is close to $64 \mu \mathrm{m} \mathrm{m}^{-1}{ }^{\circ} \mathrm{C}^{-1}$ while composites with different ELO content offer remarkably higher values of $87 \mu \mathrm{m} \mathrm{m}^{-1}{ }^{\circ} \mathrm{C}^{-1}$ and $102 \mu \mathrm{m} \mathrm{m}^{-1}{ }^{\circ} \mathrm{C}^{-1}$ for composites with 7.5 wt.\% HSF and 22.5 wt.\% HSF respectively. This is in total accordance with the plasticization effect provided by ELO as it allows chain mobility, which is more pronounced with temperature.

\section{Table 4}

The evolution of the CLTE over $\mathrm{T}_{\mathrm{g}}$ follows similar tendency with a change from $157.7 \mu \mathrm{m} \mathrm{m}^{-1}{ }^{\circ} \mathrm{C}^{-1}$ (unmodified composite) up to values of 175.8 for the composite with 22.5 wt.\% ELO. As we have observed, the CLTE is characterized by lower values below $\mathrm{T}_{\mathrm{g}}$ as the chain mobility is restricted. On the other hand, CLTE values are higher over $\mathrm{T}_{\mathrm{g}}$ due to a remarkable increase in chain mobility which is also more pronounced by the plasticization effect provided by ELO.

In addition to dimensional stability by TMA analysis, other thermo-mechanical properties have been evaluated. Fig. 5 shows the plot evolution of the Vicat softening temperature (VST) and heat deflection temperature (HDT) of PLA - 20 wt.\% HSF composites with varying ELO content. As these two thermal parameters are directly related to mechanical resistant properties we observe the same tendency of that observed for strength and modulus. The initial VST and HDT values for unmodified composite are $54.5{ }^{\circ} \mathrm{C}$ and $53.1{ }^{\circ} \mathrm{C}$ respectively which indicate that moderate temperatures lead to material softening. Regarding the VST evolution in terms of wt.\% ELO, plasticization provided by ELO leads to more soft and flexible materials so that, VST values decrease with increasing ELO content up to values of $51.1^{\circ} \mathrm{C}, 50.5{ }^{\circ} \mathrm{C}$ and $48.3{ }^{\circ} \mathrm{C}$ for an ELO 
content of 7.5 wt. $\%, 15$ wt. $\%$ and 22.5 wt.\% respectively. Epoxidized linseed oil acts as a plasticizer which leads to a clear softening effect which is more pronounced by the application of external loads at lower temperature values. Sliding of polymer chains is easier in the presence of epoxidized linseed oil molecules since these diminish the intermolecular attraction forces between individual poly(lactic) acid macromolecules[42]. The evolution of the heat deflection temperature (HDT) is similar to that observed for VST. The HDT of unmodified composite $\left(51.6^{\circ} \mathrm{C}\right)$ is reduced up to $49^{\circ} \mathrm{C}$ for composites containing 22.5 wt. $\%$ ELO.

\section{Figure 5}

\section{Figure 6}

The plasticization effect of ELO can also be detected by dynamic mechanical thermal analysis (DMTA). Fig. 6 shows a plot evolution of the storage modulus (G'). We can see that all DMTA curves for composites containing different ELO amounts are located below the curve for unmodified composite. Below the glass transition temperature $\left(\mathrm{T}_{\mathrm{g}}\right)$, the storage modulus $\left(\mathrm{G}^{\prime}\right)$ is high due to an elastic-vitreous behavior. In this first section the maximum $G^{\prime}$ values are obtained for unmodified PLA - 20 wt.\% composite with a value around $1952 \mathrm{MPa}$. As one can see, the initial storage modulus decreases as the ELO content increases with values of $1705 \mathrm{MPa}, 1352 \mathrm{MPa}$ and $1049 \mathrm{MPa}$ for composites containing $7.5 \mathrm{wt} . \%, 15 \mathrm{wt} . \%$ and $22.5 \mathrm{wt} . \%$ respectively. Once the glass transition temperature is overpassed, we observe a remarkable decrease in G' due to an elastic-viscous behavior. The temperature range of this softening process is remarkably lower for composites with high wt.\% ELO content. This softening temperature range 
changes from $\left[64^{\circ} \mathrm{C}-85^{\circ} \mathrm{C}\right]$ for unmodified composite up to $\left[50^{\circ} \mathrm{C}-65^{\circ} \mathrm{C}\right]$ for composites with an ELO content of $22.5 \mathrm{wt} . \%$. This is in total accordance with previous results as ELO enhances polymer chain motion, which leads to a softer material. So that, at $60{ }^{\circ} \mathrm{C}$, the storage modulus $\left(\mathrm{G}^{\prime}\right)$ of unmodified composite is close to $1081{ }^{\circ} \mathrm{C}$ while this is remarkably reduced up to values of $467 \mathrm{MPa}$ for composites with $7.5 \mathrm{wt} \%$ ELO due to the plasticizing-softening effect provided by ELO. These values are even extremely lower for composites containing $15 \mathrm{wt} . \%$ and $22.5 \mathrm{wt}$. $\%$ ELO with G' values of $6.2 \mathrm{MPa}$ and 3.4 MPa respectively[43, 47]. Over $90^{\circ} \mathrm{C}$, unplasticized composite from PLA and 20 wt.\% HSF shows an increase in the storage modulus which is directly related to the cold crystallization process. As we can see, presence of ELO in PLA-HSF composites leads to a remarkable decrease in the cold crystallization onset temperature with values of about $85^{\circ} \mathrm{C}, 70^{\circ} \mathrm{C}$ and $65^{\circ} \mathrm{C}$ for composites containing 7.5 wt. $\%, 15$ wt. $\%$ and 22.5 wt. $\%$ ELO. This behavior is related to increased chain mobility over the glass transition temperature, which allows chain rearrangement to ordered/packed structures at lower temperatures. During the cold crystallization process, both density and stiffness increase to the highly packed structure $[16,28]$. Once the crystallization process is completed, the evolution of the storage modulus $\left(G^{\prime}\right)$ follows similar tendency as observed in the initial stages with maximum values for unmodified composites and decreasing values with higher ELO content.

\section{Figure 7}

With regard to the damping factor $(\tan \delta$ ) Fig. 7 shows its evolution with temperature for PLA - HSF composites. As the ELO content increases, the damping peak is moved to lower temperature. This peak is related to the glass transition due to a change 
in behavior from elastic to viscous material. By taking the damping peak as a representative value of the glass transition temperature $\left(\mathrm{T}_{\mathrm{g}}\right)$ we can see that unmodified PLA - HSF composite is characterized by a $\mathrm{T}_{\mathrm{g}}$ of $75^{\circ} \mathrm{C}$ and this is remarkably reduced with increasing ELO content up to values of $72{ }^{\circ} \mathrm{C}, 60^{\circ} \mathrm{C}$ and $57^{\circ} \mathrm{C}$ for PLA $-\mathrm{HSF}$ composites containing $7.5 \mathrm{wt} . \%, 15 \mathrm{wt} . \%$ and $22.5 \mathrm{wt} . \%$ ELO respectively. As indicated previously, ELO provides good plasticizing effect on PLA - HSF composites and is evidenced by a decrease in the damping peak that is representative of a decrease in the glass transition temperature[22-24, 42, 45, 51].

The evolution of the storage modulus and the damping factor indicate that low ELO content gives similar behavior to unmodified composite with a rigid behavior. For these compositions, the plasticization effect is not important and some coupling effect can be achieved by ELO. On the other hand, when high contents of ELO are used flexible materials are obtained with a clear plasticization effect evidenced by a decrease in the glass transition temperature and, furthermore, optimum coupling effects are provided by ELO thus leading to composites with improved overall properties. In addition to mechanical properties, ELO provides a lubricant effect that enables manufacturing of PLA-based composites with a remarkable decrease in viscosity even with presence of filler particles[16, 47].

\section{4.- Conclusions}

The effect of varying epoxidized linseed oil (ELO) content on overall properties of poly(lactic acid), PLA composites with constant $20 \mathrm{wt} \% \%$ hazelnut shell flour (HSF) has been studied. The obtained results have revealed a dual effect provided by ELO: on the one hand it contributes to plasticize PLA with a noticeable decrease in the glass transition temperature and on the other hand, ELO acts as coupling agent with potential 
interactions with hydroxil groups from both lignocellulosic filler and terminal groups in poly(lactic acid) macromolecular chains. A synergistic effect is provided by ELO which enhances overall properties of PLA - HSF composites.

With regard to mechanical properties, presence of ELO leads to lower resistant properties such as tensile and flexural strength, elastic and flexural modulus and Shore D hardness but a remarkable increase in ductile properties is achieved with increasing amounts of ELO. The elongation at break changes from $3.1 \%$ for the unmodified PLA 20 wt. $\%$ HSF composite up to values of $17 \%$ for the composite containing 22.5 wt. $\%$ ELO in its composition. ELO provides a clear plasticizing effect, particularly for ELO content over 7.5 wt.\%. Epoxidized linseed oil (ELO) molecules are placed between individual poly(lactic acid) macromolecules and contribute to diminish intermolecular attraction forces between polymer chains and this enhances chain mobility with a positive effect on deformation mechanisms. In addition, the coupling effect of ELO has been evidenced by field emission electron scan microcopy (FESEM) with a remarkable decrease of the gap among the filler-matrix interface area.

Regarding thermal properties of PLA - $20 \mathrm{wt} . \% \mathrm{HSF}$ it is important to note an important decrease in the glass transition temperature by differential scanning calorimetry, DSC (about $8^{\circ} \mathrm{C}$ lower for the composite with $22.5 \mathrm{wt} . \%$ ELO) and dynamic mechanical thermal analysis, DMTA (about $15^{\circ} \mathrm{C}$ lower for the same composition)

In general terms, attractive synergistic plasticization and coupling effects can be obtained by adding epoxidized linseed oil (ELO) to green composites based on poly(lactic acid) matrix and hazelnut shell flour (HSF) without further modifications. The resulting materials offer improved ductile properties and easy manufacturing due to the plasticization effect of ELO and overall mechanical properties are obtained due to the coupling effect between the lignocellulosic filler and polylactic acid. 


\section{Acknowledgements}

This research was supported by the Ministry of Economy and Competitiveness -

MINECO, Ref: MAT2014-59242-C2-1-R. Authors also thank to "Conselleria d'Educació, Cultura i Esport" - Generalitat Valenciana, Ref: GV/2014/008 for financial support.

\section{References}

1. Ferrero, B., et al., Green Composites Based on Wheat Gluten Matrix and Posidonia Oceanica Waste Fibers as Reinforcements. Polymer Composites, 2013. 34(10): p. 16631669.

2. Ferrero, B., et al., Development of natural fiber-reinforced plastics (NFRP) based on biobased polyethylene and waste fibers from Posidonia oceanica seaweed. Polymer Composites, 2015. 36(8): p. 1378-1385.

3. Garcia-Garcia, D., et al., Green composites based on polypropylene matrix and hydrophobized spend coffee ground (SCG) powder. Composites Part B-Engineering, 2015. 78: p. 256-265.

4. Khalil, H.P.S.A., et al., Natural fiber reinforced poly(vinyl chloride) composites: A review. Journal of Reinforced Plastics and Composites, 2013. 32(5): p. 330-356.

5. Spiridon, I., I. NATURAL FIBER-POLYOLEFIN COMPOSITES. MINI-REVIEW. Cellulose Chemistry and Technology, 2014. 48(7-8): p. 599-611.

6. Zahedi, M., et al., Utilization of natural montmorillonite modified with dimethyl, dehydrogenated tallow quaternary ammonium salt as reinforcement in almond shell flour-polypropylene bio-nanocomposites. Composites Part B-Engineering, 2015. 71: p. 143-151.

7. Ashori, A., Wood-plastic composites as promising green-composites for automotive industries! Bioresource Technology, 2008. 99(11): p. 4661-4667.

8. Martin, O. and L. Averous, Poly(lactic acid): plasticization and properties of biodegradable multiphase systems. Polymer, 2001. 42(14): p. 6209-6219.

9. Perinovic, S., B. Andricic, and M. Erceg, Thermal properties of poly(L-lactide)/olive stone flour composites. Thermochimica Acta, 2010. 510(1-2): p. 97-102.

10. Arao, Y., et al., Strength improvement in injection-molded jute-fiber-reinforced polylactide green-composites. Composites Part B-Engineering, 2015. 68: p. 200-206.

11. Copur, Y., et al., Some chemical properties of hazelnut husk and its suitability for particleboard production. Building and Environment, 2007. 42(7): p. 2568-2572.

12. Kim, K.-W., et al., Thermal and mechanical properties of cassava and pineapple floursfilled PLA bio-composites. Journal of Thermal Analysis and Calorimetry, 2012. 108(3): p. 1131-1139.

13. Koronis, G., A. Silva, and M. Fontul, Green composites: A review of adequate materials for automotive applications. Composites Part B-Engineering, 2013. 44(1): p. 120-127.

14. Li, Y., K. Venkateshan, and X.S. Sun, Mechanical and thermal properties, morphology and relaxation characteristics of poly(lactic acid) and soy flour/wood flour blends. Polymer International, 2010. 59(8): p. 1099-1109.

15. Salasinska, K. and J. Ryszkowska, Natural fibre composites from polyethylene waste and hazelnut shell: dimensional stability, physical, mechanical and thermal properties. Composite Interfaces, 2012. 19(5): p. 321-332. 
16. Shah, B.L., et al., Effects of wood flour and chitosan on mechanical, chemical, and thermal properties of polylactide. Polymer Composites, 2008. 29(6): p. 655-663.

17. Shih, Y.-F. and C.-C. Huang, Polylactic acid (PLA)/banana fiber (BF) biodegradable green composites. Journal of Polymer Research, 2011. 18(6): p. 2335-2340.

18. Shih, Y.-F., C.-C. Huang, and P.-W. Chen, Biodegradable green composites reinforced by the fiber recycling from disposable chopsticks. Materials Science and Engineering aStructural Materials Properties Microstructure and Processing, 2010. 527(6): p. 15161521.

19. Stevigny, C., et al., Optimization of extraction of phenolic content from hazelnut shell using response surface methodology. Journal of the Science of Food and Agriculture, 2007. 87(15): p. 2817-2822.

20. Xu, Y., et al., Nutritional composition and antioxidant activity in hazelnut shells from USgrown cultivars. International Journal of Food Science and Technology, 2012. 47(5): p. 940-946.

21. Yussuf, A.A., I. Massoumi, and A. Hassan, Comparison of Polylactic Acid/Kenaf and Polylactic Acid/Rise Husk Composites: The Influence of the Natural Fibers on the Mechanical, Thermal and Biodegradability Properties. Journal of Polymers and the Environment, 2010. 18(3): p. 422-429.

22. Burgos, N., V.P. Martino, and A. Jimenez, Characterization and ageing study of poly(lactic acid) films plasticized with oligomeric lactic acid. Polymer Degradation and Stability, 2013. 98(2): p. 651-658.

23. Chieng, B.W., et al., Epoxidized Vegetable Oils Plasticized Poly(lactic acid) Biocomposites: Mechanical, Thermal and Morphology Properties. Molecules, 2014. 19(10): p. 1602416038.

24. Chieng, B.W., et al., Plasticized Poly(lactic acid) with Low Molecular Weight Poly(ethylene glycol): Mechanical, Thermal, and Morphology Properties. Journal of Applied Polymer Science, 2013. 130(6): p. 4576-4580.

25. Liu, H. and J. Zhang, Research Progress in Toughening Modification of Poly(lactic acid). Journal of Polymer Science Part B-Polymer Physics, 2011. 49(15): p. 1051-1083.

26. Murariu, M., et al., Polylactide (PLA) designed with desired end-use properties: 1. PLA compositions with low molecular weight ester-like plasticizers and related performances. Polymers for Advanced Technologies, 2008. 19(6): p. 636-646.

27. Shinyama, K., S. Fujita, and J. Inst Elect Engineers, The Effects of Plasticizer on the Mechanical and Electrical Characteristics of PLA. Iseim 2008: Proceedings of 2008 International Symposium on Electrical Insulating. 2008. 85-85.

28. $\mathrm{Yu}, \mathrm{Y}$, , et al., Plasticizing effect of poly(ethylene glycol)s with different molecular weights in poly(lactic acid)/starch blends. Journal of Applied Polymer Science, 2015. 132(16).

29. Zhang, C., et al., Thermal, mechanical and rheological properties of polylactide toughened by expoxidized natural rubber. Materials \& Design, 2013. 45: p. 198-205.

30. Faludi, G., et al., Improving interfacial adhesion in pla/wood biocomposites. Composites Science and Technology, 2013. 89: p. 77-82.

31. Altun, Y., M. Dogan, and E. Bayramli, Effect of Alkaline Treatment and Pre-impregnation on Mechanical and Water Absorbtion Properties of Pine Wood Flour Containing Poly (Lactic Acid) Based Green-Composites. Journal of Polymers and the Environment, 2013. 21(3): p. 850-856.

32. Gregorova, A., et al., Surface Modification of Spruce Wood Flour and Effects on the Dynamic Fragility of PLA/Wood Composites. Polymer Engineering and Science, 2011. 51(1): p. 143-150.

33. Li, Z., X. Zhou, and C. Pei, Effect of Sisal Fiber Surface Treatment on Properties of Sisal Fiber Reinforced Polylactide Composites. International Journal of Polymer Science, 2011. 
34. Lu, T., et al., Effects of modifications of bamboo cellulose fibers on the improved mechanical properties of cellulose reinforced poly(lactic acid) composites. Composites Part B-Engineering, 2014. 62: p. 191-197.

35. Pilla, S., et al., Polylactide-pine wood flour composites. Polymer Engineering and Science, 2008. 48(3): p. 578-587.

36. Sarasini, F., et al., Effect of Fiber Surface Treatments on Thermo-Mechanical Behavior of Poly(Lactic Acid)/Phormium Tenax Composites. Journal of Polymers and the Environment, 2013. 21(3): p. 881-891.

37. Wang, Y., et al., Effects of Coupling Agent and Interfacial Modifiers on Mechanical Properties of Poly(lactic acid) and Wood Flour Biocomposites. Iranian Polymer Journal, 2011. 20(4): p. 281-294.

38. Chun, K.S. and S. Husseinsyah, Polylactic acid/corn cob eco-composites: Effect of new organic coupling agent. Journal of Thermoplastic Composite Materials, 2014. 27(12): p. 1667-1678.

39. Kabir, M.M., et al., Chemical treatments on plant-based natural fibre reinforced polymer composites: An overview. Composites Part B-Engineering, 2012. 43(7): p. 2883-2892.

40. Liu, R., et al., Characterization of organo-montmorillonite (OMMT) modified wood flour and properties of its composites with poly(lactic acid). Composites Part a-Applied Science and Manufacturing, 2013. 51: p. 33-42.

41. Petchwattana, N. and S. Covavisaruch, Mechanical and Morphological Properties of Wood Plastic Biocomposites Prepared from Toughened Poly(lactic acid) and Rubber Wood Sawdust (Hevea brasiliensis). Journal of Bionic Engineering, 2014. 11(4): p. 630637.

42. Alam, J., et al., MWCNTs-Reinforced Epoxidized Linseed Oil Plasticized Polylactic Acid Nanocomposite and Its Electroactive Shape Memory Behaviour. International Journal of Molecular Sciences, 2014. 15(11): p. 19924-19937.

43. Ali, F., et al., Thermal, mechanical and rheological properties of poly (lactic acid)/epoxidized soybean oil blends. Polymer Bulletin, 2009. 62(1): p. 91-98.

44. Al-Mulla, E.A.J., et al., Properties of epoxidized palm oil plasticized polytlactic acid. Journal of Materials Science, 2010. 45(7): p. 1942-1946.

45. Prempeh, N., et al., Plasticizing Effects of Epoxidized Sun Flower Oil on Biodegradable Polylactide Films: A Comparative Study. Polymer Science Series A, 2014. 56(6): p. 856863.

46. Silverajah, V.S.G., et al., A Comparative Study on the Mechanical, Thermal and Morphological Characterization of Poly(lactic acid)/Epoxidized Palm Oil Blend. International Journal of Molecular Sciences, 2012. 13(5): p. 5878-5898.

47. Silverajah, V.S.G., et al., Mechanical, Thermal and Morphological Properties of Poly(lactic acid)/Epoxidized Palm Olein Blend. Molecules, 2012. 17(10): p. 11729-11747.

48. Du, Y., et al., Fabrication and characterization of fully biodegradable natural fiberreinforced poly(lactic acid) composites. Composites Part B-Engineering, 2014. 56: p. 717723.

49. Fischer, E.W., H.J. Sterzel, and G. Wegner, INVESTIGATION OF STRUCTURE OF SOLUTION GROWN CRYSTALS OF LACTIDE COPOLYMERS BY MEANS OF CHEMICAL-REACTIONS. Kolloid-Zeitschrift and Zeitschrift Fur Polymere, 1973. 251(11): p. 980-990.

50. Ke, T.Y. and X.Z. Sun, Effects of moisture content and heat treatment on the physical properties of starch and poly(lactic acid) blends. Journal of Applied Polymer Science, 2001. 81(12): p. 3069-3082.

51. Etaati, A., et al., The study of fibre/matrix bond strength in short hemp polypropylene composites from dynamic mechanical analysis. Composites Part B-Engineering, 2014. 62: p. 19-28. 


\section{Tables}

Table 1.- Composition (in weight \%) of poly(lactic acid), PLA - hazelnut shell flour (HSF) composites with varying epoxidized linseed oil (ELO) content.

\begin{tabular}{|c|c|c|c|}
\hline Sample & $\begin{array}{c}\text { PLA content } \\
(\text { wt. \%) }\end{array}$ & $\begin{array}{c}\text { Hazelnut shell flour (HSF) } \\
\text { content (wt. \%) }\end{array}$ & $\begin{array}{c}\text { ELO content } \\
\text { (wt. \%) }\end{array}$ \\
\hline 0-ELO & 80 & 20 & 0 \\
\hline 7.5-ELO & 72.5 & 20 & 15 \\
\hline 15-ELO & 65 & 20 & 22.5 \\
\hline 22.5-ELO & 57.5 & 20 & \\
\hline
\end{tabular}

Table 2.- Mechanical properties of PLA - HSF composites with varying epoxidized linseed oil (ELO) content.

\begin{tabular}{|c|c|c|c|c|c|c|}
\hline \multirow{2}{*}{ Sample } & \multicolumn{3}{|c|}{ Tensile } & \multicolumn{2}{c|}{ Flexural } & \multirow{2}{*}{ Hardness } \\
\cline { 2 - 6 } & Elastic & \multirow{2}{*}{ Strength } & Elongation & Modulus & Strength & Shore D \\
& $(\mathrm{MPa})$ & $(\mathrm{MPa})$ & $(\%)$ & $(\mathrm{MPa})$ & $(\mathrm{MPa})$ & \\
& & & & & & \\
\hline 0-ELO & $1019 \pm 53$ & $45.0 \pm 4.9$ & $3.1 \pm 0.4$ & $3932 \pm 92$ & $83.7 \pm 1.9$ & $75.6 \pm 0.5$ \\
\hline 7.5-ELO & $965 \pm 42$ & $34.4 \pm 1.4$ & $4.2 \pm 0.4$ & $3523 \pm 152$ & $59.6 \pm 0.9$ & $71.2 \pm 0.4$ \\
\hline 15-ELO & $751 \pm 81$ & $22.1 \pm 0.7$ & $11.2 \pm 1.8$ & $2702 \pm 287$ & $42.1 \pm 0.8$ & $67.8 \pm 0.8$ \\
\hline 22.5-ELO & $590 \pm 58$ & $15.3 \pm 0.9$ & $17.1 \pm 1.8$ & $2118 \pm 143$ & $29.5 \pm 0.9$ & $59.6 \pm 0.5$ \\
\hline
\end{tabular}


Table 3.- Thermal properties of PLA - 20 wt.\% HSF composites with varying wt.\% of epoxidized linseed oil (ELO) content, obtained by differential scanning calorimetry (DSC).

\begin{tabular}{|c|c|c|c|c|c|c|c|c|}
\hline Samples & $\begin{array}{l}\mathbf{T}_{g} \\
\left({ }^{\circ} \mathrm{C}\right)\end{array}$ & $\begin{array}{l}\mathbf{T}_{\mathrm{cc}} \\
\left({ }^{\mathbf{o}} \mathrm{C}\right)\end{array}$ & $\begin{array}{l}\Delta H_{c c} \\
\left(J^{-1}\right)\end{array}$ & $\begin{array}{l}\Delta \mathbf{H}_{\mathrm{cc}} \\
\text { corrected * } \\
\left(\mathrm{J} \mathrm{g}^{-1}\right)\end{array}$ & $\begin{array}{l}\mathbf{T}_{\mathbf{m}} \\
\left({ }^{\circ} \mathrm{C}\right)\end{array}$ & $\begin{array}{l}\Delta \mathbf{H}_{\mathrm{m}} \\
\left(\mathbf{J ~ g ~}^{-1}\right)\end{array}$ & $\begin{array}{l}\Delta \mathrm{H}_{\mathrm{m}} \\
\text { corrected * } \\
\left(\mathrm{J} \mathrm{g}^{-1}\right)\end{array}$ & $\begin{array}{l}\mathbf{X}_{\mathrm{c}} \\
(\%)\end{array}$ \\
\hline 0-ELO & 66.5 & 104.8 & 20.99 & 26.24 & 169.9 & -32.43 & -40.53 & 15 \\
\hline 7.5-ELO & 60.1 & 105.3 & 22.84 & 31.5 & 168.8 & -35.85 & -49.45 & 19 \\
\hline 15-ELO & 59.4 & 103.1 & 18.50 & 28.46 & 167.5 & -29.76 & -45.78 & 18 \\
\hline 22.5-ELO & 58.7 & 102.4 & 16.97 & 29.51 & 167.5 & -25.42 & -44.21 & 16 \\
\hline
\end{tabular}

$* \Delta \mathrm{H}_{\mathrm{cc}}$ corrected and $\Delta \mathrm{H}_{\mathrm{m}}$ corrected correspond to normalized crystallization and melt enthalpies by considering the real wt.\% PLA in composites.

Table 4.- Coefficient of linear thermal expansion (CLTE) of PLA - 20wt.\% composites with varying wt.\% of epoxidized linseed oil (ELO) content, obtained by thermomechanical analysis (TMA).

\begin{tabular}{|c|c|c|}
\hline Samples & $\begin{array}{c}\text { CLTE below Tg } \\
\left(\mu \mathrm{m} \mathrm{m} \mathbf{~}^{-1} \mathrm{C}^{-1}\right)\end{array}$ & 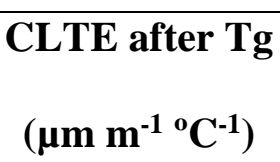 \\
\hline 0-ELO & 64.1 & 157.7 \\
\hline 7.5-ELO & 87.0 & 164.9 \\
\hline 15-ELO & 102.6 & 171.4 \\
\hline 22.5-ELO & 102.7 & 175.8 \\
\hline
\end{tabular}




\section{Figures}
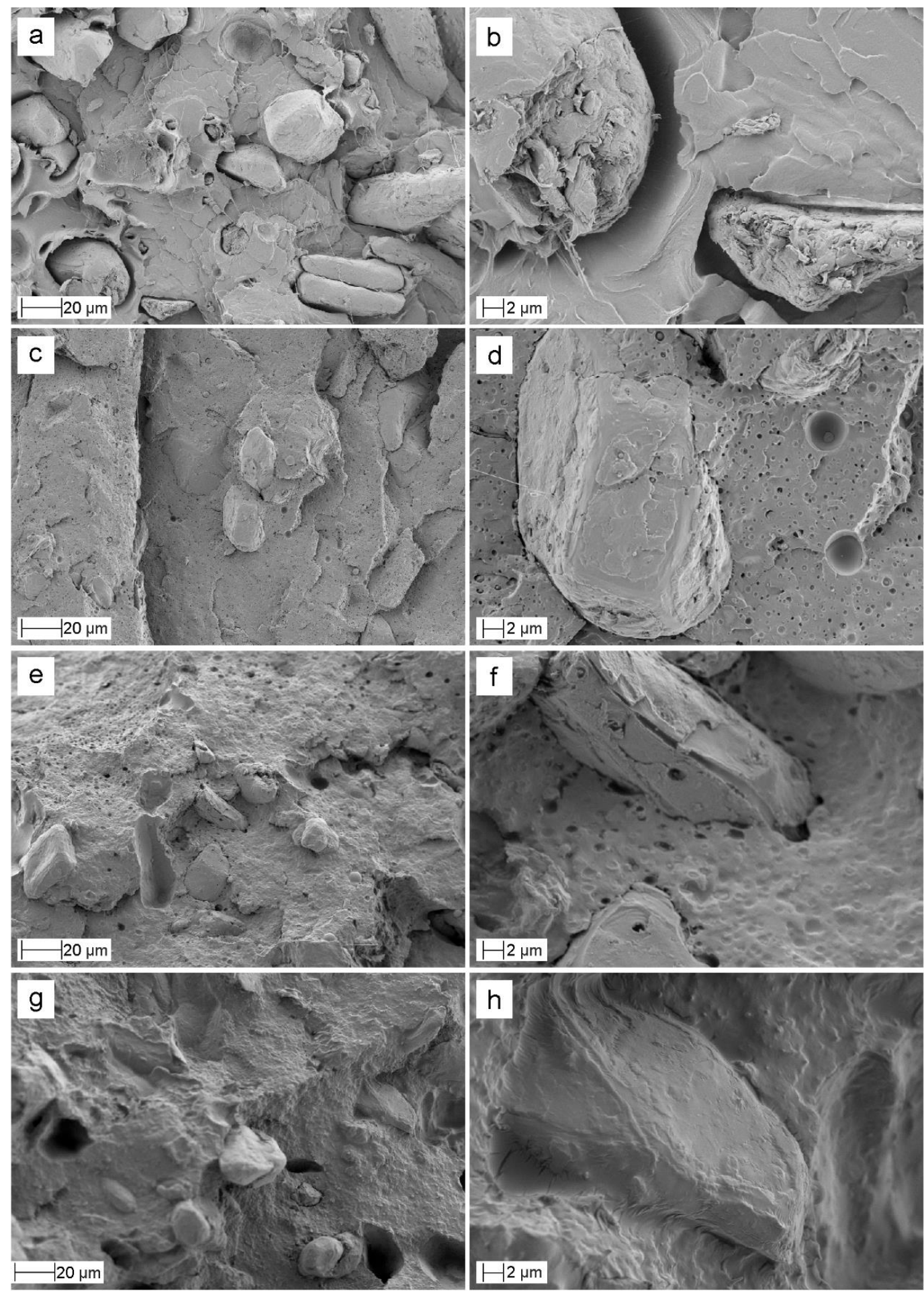

Figure 1.- FESEM images Corresponding to cryofractured surfaces from PLA - 20 wt.\% HSF and varying ELO content: a) 0 wt.\% ELO (500x); b) 0 wt.\% ELO (2500x); c) 7.5 wt.\% ELO (500x); d) 7.5 wt.\% ELO (2500x); e) 15 wt.\% ELO (500x); f) 15 wt.\% ELO (2500x); g) 22.5 wt.\% ELO (500x); h) 22.5 wt.\% ELO (2500x). 

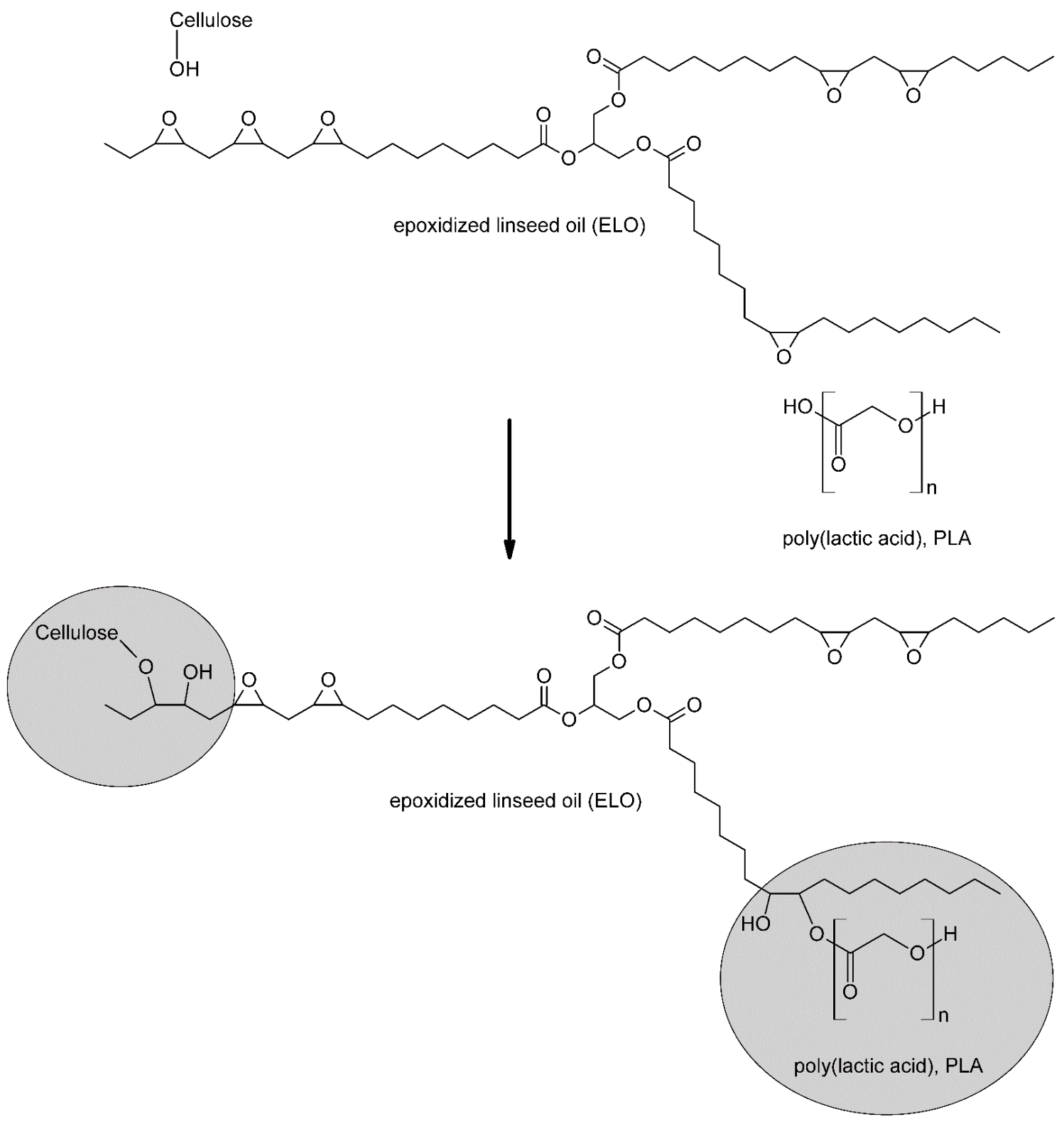

Figure 2.- Proposed chemical interactions between epoxidized linseed oil (ELO) and lignocellulosic particles from hazelnut shell flour (HSF) and ELO with poly(lactic acid) polymer chains. 


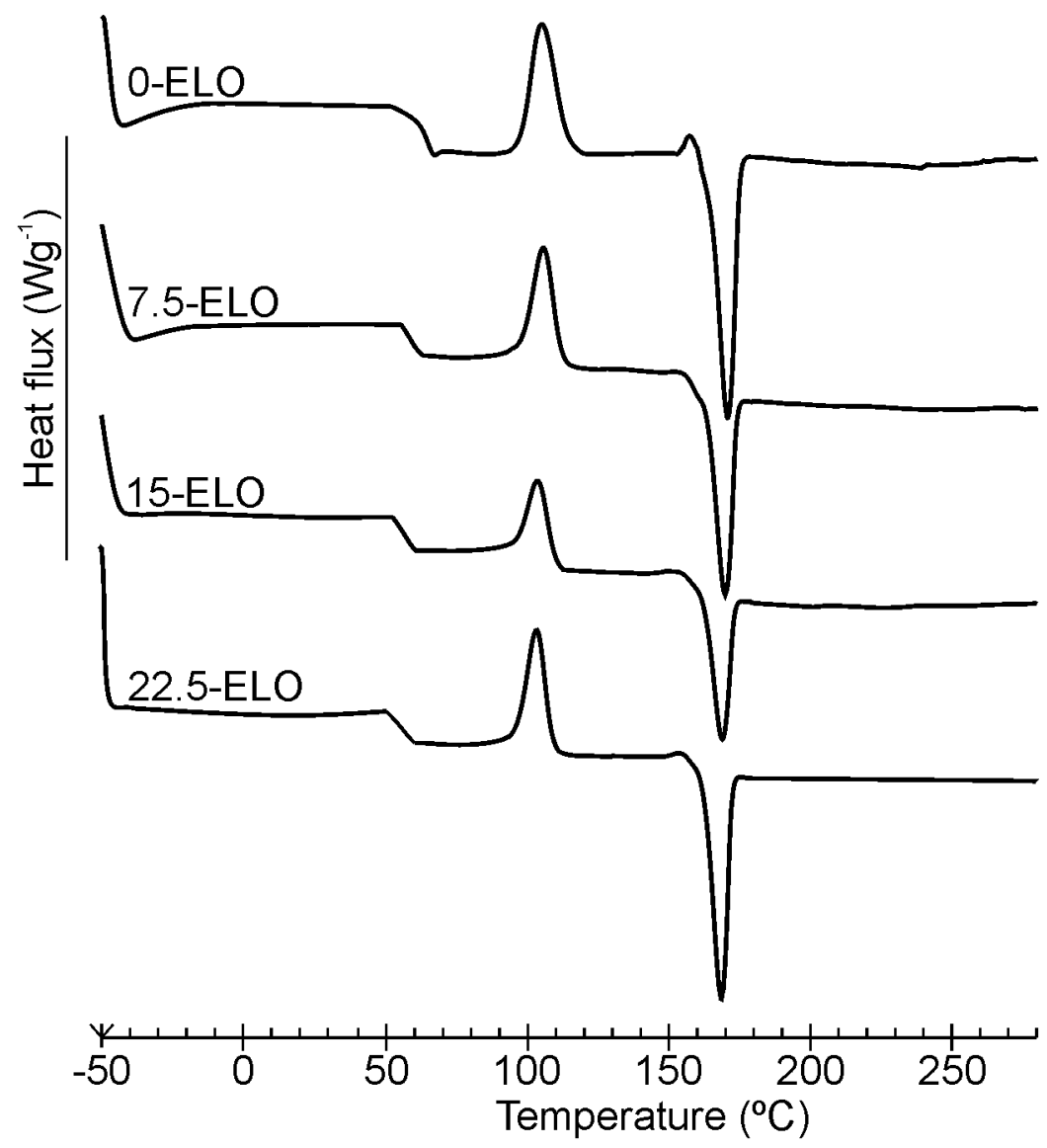

Figure 3.- Comparative plots of differential scanning calorimetry (DSC) curves of PLA -20 wt.\% HSF composites with varying wt.\% of epoxidized linseed oil (ELO) content. 


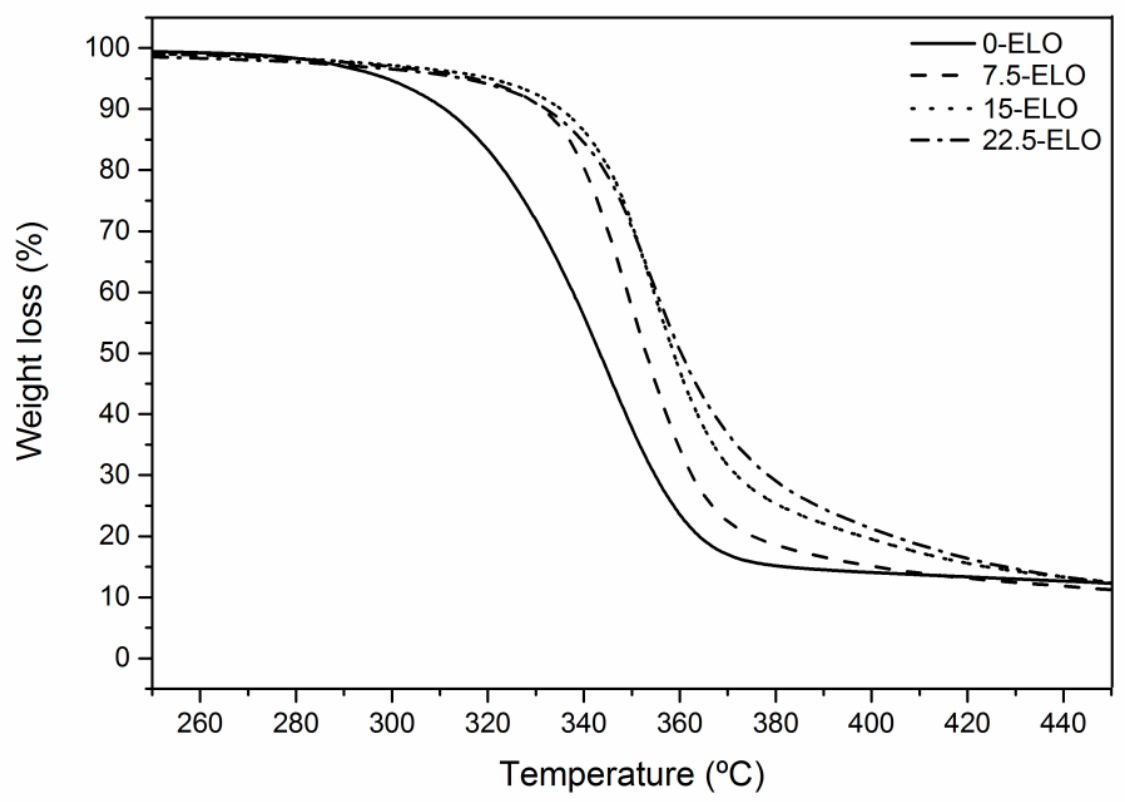

Figure 4.- Comparative plots of thermogravimetric degradation (TGA) curves of PLA 20 wt.\% HSF composites with varying wt.\% of epoxidized linseed oil (ELO) content.

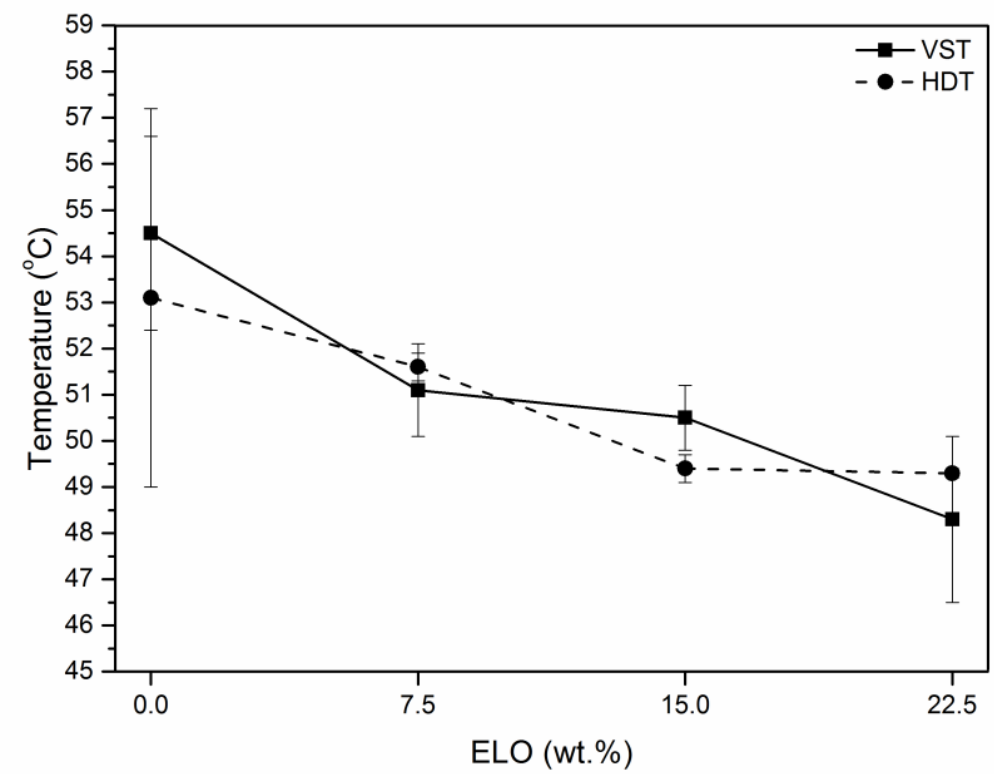

Figure 5.- Plot evolution of the Vicat softening temperature (VST) and heat deflection temperature (HDT) of PLA - 20 wt.\% HSF composites with varying wt.\% of epoxidized linseed oil (ELO) content. 


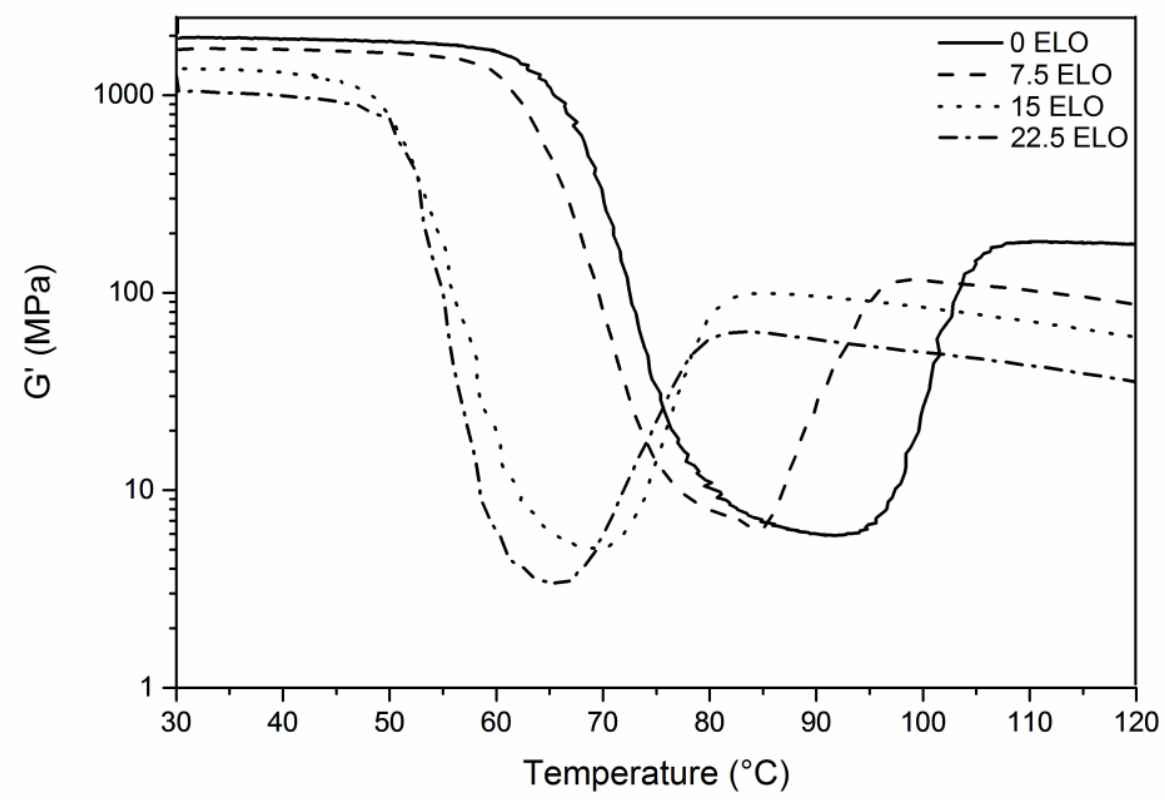

Figure 6.- Comparative plot of the storage modulus (G') of PLA - 20 wt.\% HSF composites with varying wt.\% of epoxidized linseed oil (ELO) content.

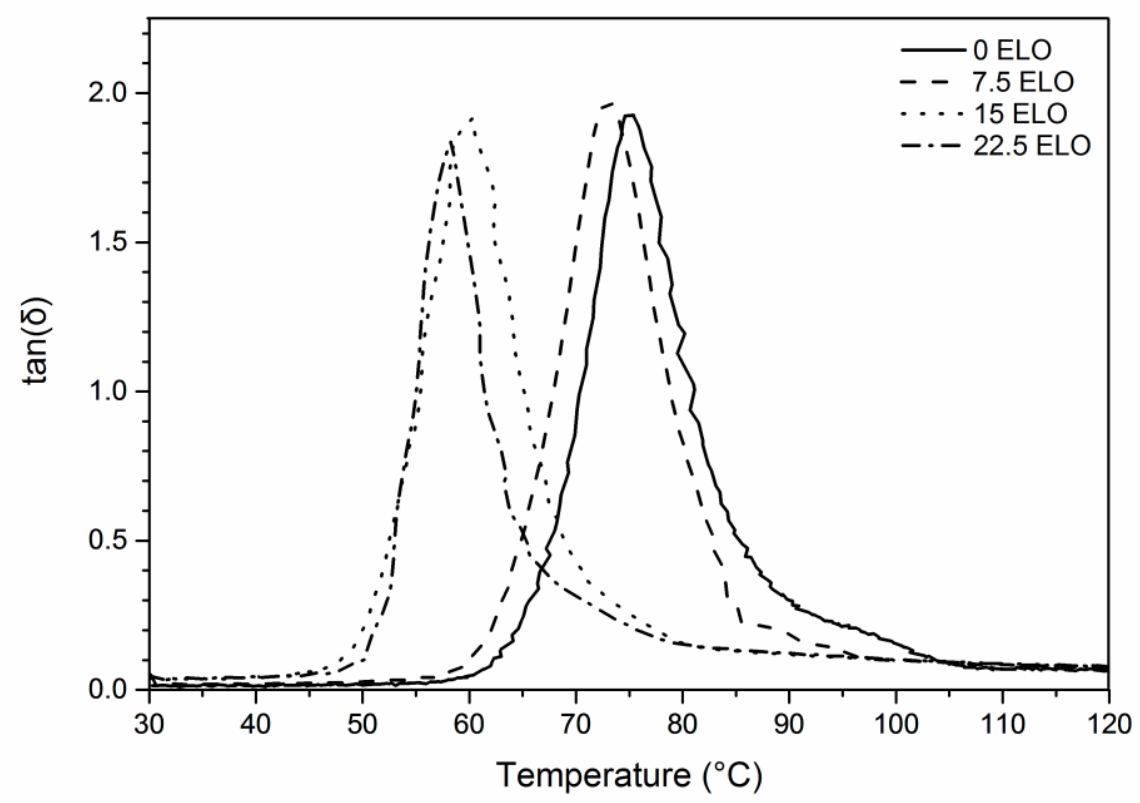

Figure 7.- Comparative plot of the damping factor $(\tan \delta$ ) of PLA - 20 wt.\% HSF composites with varying wt.\% of epoxidized linseed oil (ELO) content. 